\title{
Polymorphisms of T helper cell cytokine- associated genes and survival of hemodialysis patients - a prospective study
}

\author{
Alicja E. Grzegorzewska ${ }^{1 *}$, Monika K. Świderska², Adrianna Mostowska ${ }^{3}$, Wojciech Warchoł ${ }^{4}$ \\ and Paweł P. Jagodziński ${ }^{3}$
}

\begin{abstract}
Background: Circulating pro-inflammatory cytokines were associated with increased relative mortality risk, while immune parameters reflecting improved T-cell function were predictors of survival in hemodialysis (HD) patients. We evaluated in the prospective study whether variants in T helper cell cytokine-associated genes are determinants of mortality in HD patients.

Methods: The study was carried out in 532 prevalent HD subjects who were followed-up for 7 years. HRM analysis was used for IFNL3, IL12A, IL13, and IL4R genotyping. CCL2, IL12B, and IL18 were genotyped using PCR-RFLP analysis. Survival analyses were conducted using the Kaplan-Meier method and the Cox proportional hazard model.

Results: In univariate analyses, IFNL3 rs8099917 was associated with all-cause mortality in recessive model of inheritance (log-rank test $P=0.044$ ), IL12A rs568408 - in dominant model (log-rank test $P=0.029$ ). Minor homozygotes (the genotype GG) in IFNL3 rs8099917 showed shorter survival during the study (3.6, 1.0-7.0 years vs 4.7, 0.1-7.0 years, $P=0.009$ ) than the major allele (T) bearers. The rs $8099917 \mathrm{GG}$ patients demonstrated higher risk of death than the remaining patients $(G T+T)(\mathrm{OR} 1.94,95 \% \mathrm{Cl} 1.11-3.40, P=0.020)$. Major homozygosity (the genotype $\mathrm{GG})$ in $/ L 12 \mathrm{~A}$ rs568408 was associated with higher mortality than that shown in bearers of the minor allele (AA + AG) (HR 1.31, $95 \% \mathrm{Cl} 1.02-1.69, P=0.035)$. In multivariate analyses, however, the mentioned polymorphisms were not independent predictors of survival.
\end{abstract}

Conclusions: Polymorphisms of IFNL3 rs8099917 and IL12A rs568408 contribute to survival of HD patients, but not as independent factors.

Keywords: Cytokines, Genes, Hemodialysis, Interferon $\lambda 3$, Survival, T helper cells

\section{Background}

Cardiovascular diseases, infections and cancers are the most common causes of death in hemodialysis (HD) patients.

After an almost 3-year mean follow-up period, higher levels of circulating pro-inflammatory cytokines were significantly associated with increased relative mortality risk, while immune parameters reflecting improved T-cell function were associated with survival in HD patients,

\footnotetext{
* Correspondence: alicja_grzegorzewska@yahoo.com

${ }^{1}$ Chair and Department of Nephrology, Transplantology and Internal Diseases, Poznan University of Medical Sciences, Przybyszewskiego 49, 60-355 Poznań, Poland

Full list of author information is available at the end of the article
}

independent of other medical risk factors [1]. Interleukin (IL)-6 and anti-/pro-inflammatory cytokine balance expressed as (IL-4 + IL-10)/IL-6 ratio were associated with an enhanced hazard ratio of cardiovascular mortality in HD patients [2]. Functional imbalance between regulatory $\mathrm{T}$ cells and $\mathrm{T}$ helper (Th) cells was also found as a contributor to the high incidence of cardiovascular events in this group [3]. Th1/Th2 cytokine balance evaluated by $[\mathrm{IL}-4+$ IL-6 + IL-10)/(IL-2 + interferon (IFN)- $\gamma]$ ratio was associated with non-cardiovascular (infection, malnutrition/decline, and neoplasm) mortality in HD patients [2]. A shift toward Th2 cells was demonstrated as very important in the carcinogenesis, and increased levels of Th2 
cytokines are proposed as an early marker of cancer presence in the general population [4].

Polymorphisms of genes encoding Th1/Th2 cytokines were already associated with inflammatory response $[5,6]$, hypertension [7], atherosclerosis [5, 7], cardiovascular disease, comorbidity scores, functional scores, and biological/ nutritional markers [8] in dialysis patients. However, data concerning associations between polymorphisms of Th cell cytokine-associated genes in respect to survival of HD patients are scarce. There were no demonstrable associations between alleles/genotypes and combinations of genotypes of IL-6, tumor necrosis factor-alpha, and IL-10 and mortality of HD patients in the HEMO Study [8]. In our retrospective study, the IL13 rs20541 T allele and IFNL3 rs8099917 GG genotype were negative predictors of survival in patients requiring renal replacement therapy, while the IFNL3 rs12979860 TT genotype increased the risk of death only in patients negative for hepatitis $B$ virus (HBV) or hepatitis C virus (HCV) infections [9]. Retrospective studies have drawbacks, including biases in the selection of patients. Therefore, our aim was to evaluate in the 7-year prospective study whether variants in selected Th cell cytokine-associated genes are determinants of mortality in prevalent HD patients.

\section{Methods}

\section{Patients}

HD patients living in the Greater Poland District, Poland, were enrolled into the prospective, observational study in January, 2009. Known status in respect to HBV susceptibility or infection was an inclusion criterion, because the ability to produce antibodies to HBV surface antigen (anti-HBs) was one of parameters investigated as a predictor of survival [10]. An exclusion criterion was renal transplantation prior to enrolment. Patients were in stable clinical condition for at least one month prior to enrolment.

Characteristics of enrolled patients $(n=532)$ are shown in our previous publication [10]. In brief, the study included 297 men and 235 women in the age of 61.2 (14.6-89.3) years. Dialysis vintage prior to the study onset was $2.2(0.0-24.7)$ years. The main cause of endstage renal disease was diabetic nephropathy $(n=137$, $25.8 \%$ of all). Patients were dialyzed using low-flux HD ( $n=277,52.0 \%$ of all), high-flux HD ( $n=217,40.8 \%$ of all), and on-line hemodiafiltration $(n=38,7.1 \%$ of all).

Patients were followed from January 30, 2009 to January 30,2016 . The study was planned initially to January 30 , 2015, however, we decided to prolong the patient monitoring for the additional year to evaluate a possible association of genetic factors with survival [11]. During the 7-year prospective study, 317 (59.6\% of all) patients died, 66 (12.4\% of all) underwent renal transplantation, and 7 (1.3\% of all) moved to non-collaborating dialysis centers. Main causes of death included cardiovascular ( $n=203,64.0 \%$ of all deaths), infection ( $n=39,12.3 \%$ of all deaths), and neoplasm $(n=30,9.5 \%$ of all deaths) reasons.

\section{Genotyping}

High-resolution melting curve (HRM) analysis was used for interferon lambda 3 gene (IFNL3), interleukin 12A gene (IL12A), interleukin 13 gene (IL13), and interleukin 4 receptor gene (IL4R) genotyping. Chemokine (C-C motif) ligand 2 gene (CCL2), interleukin 12B gene (IL12B), and interleukin 18 gene (IL18) were genotyped using the polymerase chain reaction-restriction fragment length polymorphism (PCR-RFLP) analysis. Genotyping was performed as previously described $[9,11-13]$.

In brief, genomic DNA for genotype analyses was isolated from peripheral blood lymphocytes by a salt-out extraction procedure. The characteristics of analyzed polymorphisms are described in Additional file 1: Table S1. Primer sequences and conditions for PCR-RFLP and HRM analyses are presented in Additional file 1: Table S2. Approximately $10 \%$ of the randomly chosen samples were re-genotyped. Samples that failed the genotyping were excluded from further statistical analyses.

Genotyping of tested single nucleotide polymorphisms (SNPs) was performed in groups of 418-524 patients (Additional file 1: Table S3).

\section{Statistical methods}

The results are presented as numbers and percentages for categorical variables. Medians and ranges for continuous variables are shown as data sets were non-normally distributed by the Shapiro-Wilk test in the majority of subgroups.

The Hardy-Weinberg equilibrium was analyzed to compare the observed genotype frequencies to the expected ones using the Chi-square test $(P>0.05$ with $\mathrm{df}=1$ for equilibrium).

Survival analyses were conducted using the KaplanMeier method with the log rank test or with calculation of multiple $P$ value when more than two groups were compared. The Cox proportional hazard model was applied to show whether and to which extend the effect of a unit increase in a covariate was multiplicative with respect to the hazard rate of death.

Cox proportional hazard model was also applied in multivariate analyses assessing the contribution of demographics and clinical measures to mortality.

An effect size for the power equal to 0.8 was estimated for Mann-Whitney test and Chi-square test. The power of any test was calculated for statistically significant outcomes.

Abovementioned statistical analyses were performed using Graph-Pad InStat 3.10, 32 bit for Windows (GraphPad Software, Inc., San Diego, California, United 
States), Statistica version 12 (Stat Soft, Inc., Tulsa, Oklahoma, United States), and G*Power 3.1.9.2 (Franz Faul, Universitat Kiel, Germany).

Haplotype frequencies were estimated using the Haploview 4.2 software (http://www.broad.mit.edu/mpg/haploview/). Statistical significance was assessed using the 1000-fold permutation test.

Epistatic interactions were analyzed using the logistic regression and epistasis option in the PLINK software (http://pngu.mgh.harvard.edu/purcell/plink/).

A $P$ value of less than 0.05 was considered significant.

\section{Results}

At the beginning of the study, all tested polymorphisms were in concordance with HWE (Additional file 1: Table S3).

\section{Univariate survival analyses}

In univariate survival analyses, longer survival was attributed to chronic glomerulonephritis and polycystic kidney disease as causes of end-stage renal disease (ESRD), and the ability to develop anti-HBs in response to HBV vaccination or infection. Shorter survival was demonstrated in patients with older age at the beginning of the study, coronary artery disease (CAD), diabetic nephropathy, and lower serum parathyroid hormone (PTH) concentrations. The details of abovementioned analyses are shown in our earlier paper [11].

IFNL3 rs8099917 was associated with all-cause mortality in recessive model of inheritance, IL12A rs568408 - in dominant model (Table 1). Both these associations were relatively weak $(P=0.044$ for IFNL3 rs8099917 and $P=0.029$ for $I L 12 A$ rs568408).

Minor homozygotes (the genotype GG) in IFNL3 rs8099917 showed shorter survival during the study (3.6, $1.0-7.0$ years vs $4.7,0.1-7.0$ years, $P=0.009$ ) than the major allele $(\mathrm{T})$ bearers, although their renal replacement therapy (RRT) vintage prior to the onset of the study was also shorter (1.4, 0.0-6.8 years vs 2.3, 0.022.2 years, $P=0.010$ ) (Additional file 1 : Table S4). The rs8099917 GG patients demonstrated higher risk of death (HR 1.944, 95\% CI 1.112-3.401) than the remaining patients $(\mathrm{GT}+\mathrm{TT})$, (Fig. 1).

Major homozygosity (the genotype GG) in IL12A rs568408 was associated with higher mortality (HR 1.313, 95\% CI 1.20-1.691) than that shown in bearers of the minor allele (AA + AG) (Fig. 2). There were 9.7\% less responders to $\mathrm{HBV}$ vaccination in $\mathrm{HBV}$ non-infected patients showing the genotype GG compared with patients harboring the minor allele in rs568408 (Additional file 1: Table S5).

There were no significant associations between cardiovascular (Additional file 1: Table S6), infection-related (Additional file 1: Table S7) or neoplasm-related (Additional file 1: Table S8) mortalities and tested polymorphisms.

\section{Multivariate analyses of survival}

Basic variables that yielded significance in univariate analyses of survival (age at the beginning of the study,

Table 1 Differences in all-cause mortality by T helper cell cytokine genes in hemodialysis patients

\begin{tabular}{|c|c|c|c|c|c|}
\hline Tested polymorphism & $\mathrm{N}$ & $\begin{array}{l}\text { Major homozytes vs. heterozygotes } \\
\text { vs. minor homozygotes }{ }^{a}\end{array}$ & $\begin{array}{l}\text { Dominant model of } \\
\text { inheritance }^{b}\end{array}$ & $\begin{array}{l}\text { Recessive model of } \\
\text { inheritance }\end{array}$ & $\begin{array}{l}\text { Additive model of } \\
\text { inheritance }\end{array}$ \\
\hline CCL2 rs1024611 & 261 & $\begin{array}{l}\text { AA vs. AG vs. GG } \\
P=0.848\end{array}$ & $\begin{array}{l}G G+A G \text { vs. AA } \\
P=0.363\end{array}$ & $\begin{array}{l}\text { GG vs. AG + AA } \\
P=0.777\end{array}$ & $\begin{array}{l}\text { GG vs. AA } \\
P=0.601\end{array}$ \\
\hline IFNL3 rs8099917 & 265 & $\begin{array}{l}\text { T vs. GT vs. GG } \\
P=0.139\end{array}$ & $\begin{array}{l}\text { GG + GT vs. TT } \\
P=0.688\end{array}$ & $\begin{array}{l}\text { GG vs. GT }+\pi T \\
P=0.044^{c}\end{array}$ & $\begin{array}{l}\text { GG vs. TT } \\
P=0.052\end{array}$ \\
\hline IFNL3 rs12979860 & 266 & $\begin{array}{l}\text { CC vs. CT vs. TT } \\
P=0.394\end{array}$ & $\begin{array}{l}T+C T \text { vs. CC } \\
P=0.896\end{array}$ & TT vs. $C T+C C P=0.490$ & $\begin{array}{l}\text { Tा vs. CC } \\
P=0.640\end{array}$ \\
\hline IL4R rs1805015 & 294 & $\begin{array}{l}\text { T vs. CT vs. CC } \\
P=0.829\end{array}$ & $\begin{array}{l}C C+C T \text { vs. TT } \\
P=0.703\end{array}$ & $\begin{array}{l}\text { CC vs. CT }+\pi \\
P=0.352\end{array}$ & $\begin{array}{l}\text { CC vs. TT } \\
P=0.348\end{array}$ \\
\hline IL12A rs568408 & 297 & GG vs. AG vs. AA $P=0.034$ & $A A+A G$ vs. GG $P=0.029^{d}$ & $\begin{array}{l}\text { AA vs. } A G+G G \\
P=0.816\end{array}$ & $\begin{array}{l}\text { AA vs. GG } \\
P=0.958\end{array}$ \\
\hline IL $12 B$ rs3212227 & 297 & $\begin{array}{l}\text { AA vs. AC vs. CC } \\
P=0.274\end{array}$ & $\begin{array}{l}C C+A C \text { vs. } A A \\
P=0.163\end{array}$ & $\begin{array}{l}\text { CC vs. AC }+ \text { AA } \\
P=0.104\end{array}$ & $\begin{array}{l}\text { CC vs. AA } \\
P=0.087\end{array}$ \\
\hline IL 13 rs20541 & 293 & $\begin{array}{l}C C \text { vs. } C T \text { vs. TT } \\
P=0.412\end{array}$ & $\begin{array}{l}\Pi T+C T \text { vs. } C C \\
P=0.189\end{array}$ & TT vs. $C T+C C P=0.981$ & $\begin{array}{l}\text { TT vs. CC } \\
P=0.803\end{array}$ \\
\hline IL18 rs360719 & 316 & $\begin{array}{l}\text { T vs. CT vs. CC } \\
P=0.651\end{array}$ & $\begin{array}{l}C C+C T \text { vs. TT } \\
P=0.260\end{array}$ & $\begin{array}{l}\text { CC vs. CT }+\pi \\
P=0.648\end{array}$ & $\begin{array}{l}\text { CC vs. Tा } \\
P=0.484\end{array}$ \\
\hline
\end{tabular}

Abbreviations: CCL2 chemokine (C-C motif) ligand 2 gene, IFNL3 interferon lambda 3 gene, IL interleukin gene, IL $4 R$ interleukin 4 receptor gene, $N$ number of deaths among tested patients

${ }^{a}$ Multiple-sample test $\mathrm{P}$

${ }^{b}$ Log rank test $P$

${ }^{\mathrm{C}}$ The test power $=0.98$

${ }^{\mathrm{d}}$ The test power $=0.66$ 


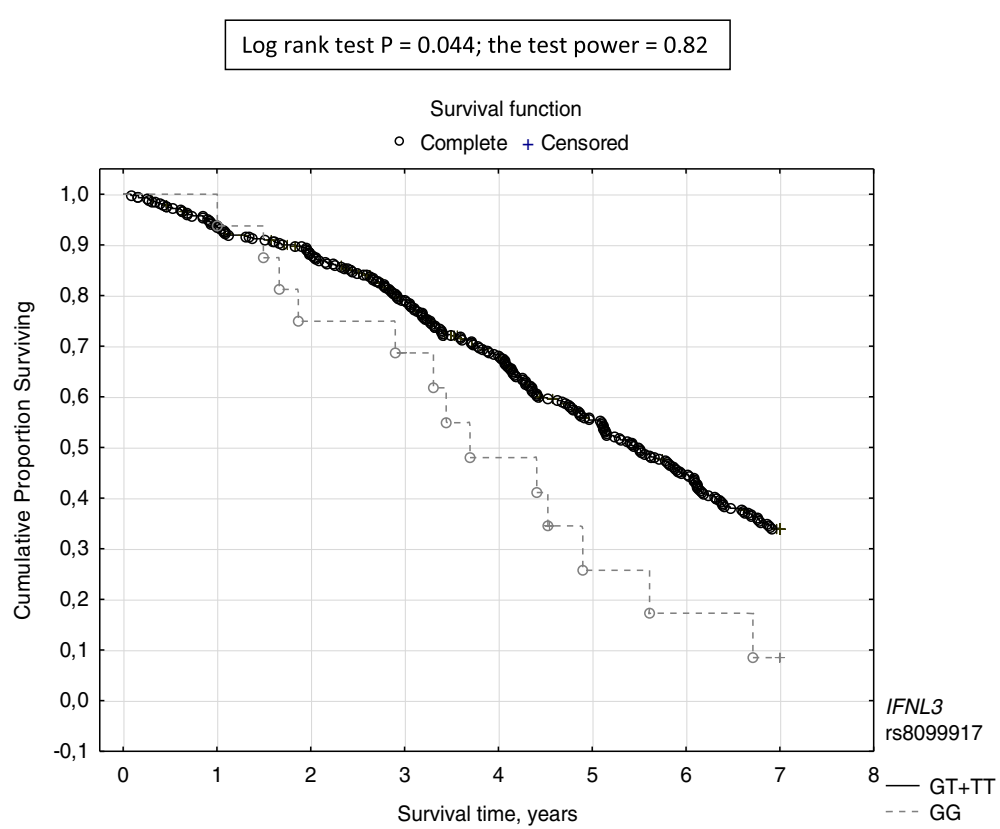

Fig. 1 The probability of survival in hemodialysis patients in respect to IFNL3 rs8099917 polymorphic variant

diabetic nephropathy, polycystic kidney disease and chronic glomerulonephritis as causes of ESRD, CAD, the ability to develop anti-HBs in response to HBV vaccination or infection, and serum PTH concentration) as well as RRT vintage prior to the study onset were used in multivariate analysis. CAD (HR 1.753, 95\% CI 1.3832.221, $P=0.000003)$, age at the beginning of the study (HR 1.019, 95\% CI 1.009-1.029, $P=0.0001$ ), RRT vintage prior to the study onset (HR 1.058, 95\% CI 1.021-1.097, $P=0.002$ ), and the ability to develop antibodies to HBV surface antigen in response to $\mathrm{HBV}$ vaccination or infection (HR 0.672, 95\% CI 0.493-0.915, $P=0.012$ ) remained as independent predictors of 7 -year survival of prevalent HD patients.

When both SNPs showing significance in univariate analyses (IFNL3 rs8099917 and IL12A rs568408) were

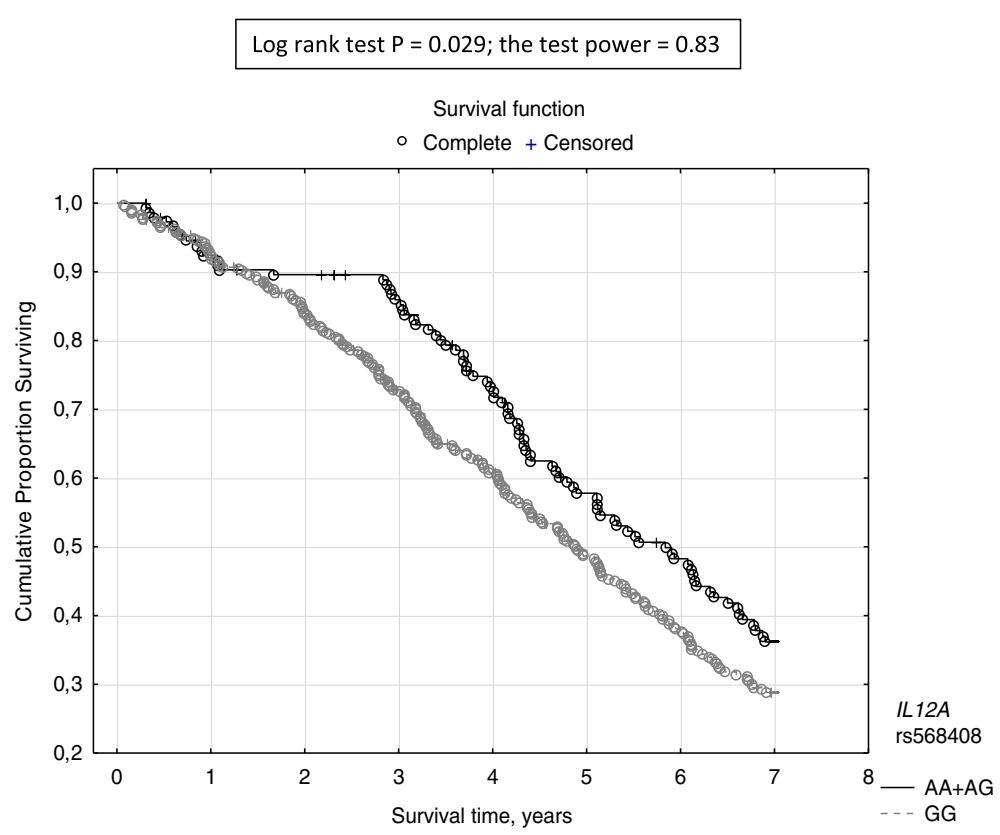

Fig. 2 The probability of survival in hemodialysis patients in respect to IL12A rs568408 polymorphic variant 
used in multivariate analyses including all 8 basic variables or only 4 variables that remained significant, the tested SNPs did not yield significance. Moreover, the ability to develop anti-HBs lost its significance as an independent predictor of survival. When IFNL3 rs8099917 and $I L 12 A$ rs568408 were used separately in multivariate analyses, only IFNL3 rs8099917 abolished significance of anti-HBs.

\section{Haplotype frequencies and epistatic interactions}

Haplotype analysis of IFNL3 polymorphic variants did not reveal significance (Additional file 1: Table S9) as well as there were no significant gene-gene interactions between tested polymorphisms (Additional file 1: Table S10) in the 7-year survivors and non-survivors.

\section{Discussion}

In this study, we were not able to show independent predictors of all-cause mortality of HD patients among tested polymorphic variants of Th cell cytokine related genes. Similarly like in our retrospective study [9], the GG genotype in IFNL3 rs8099917 was associated with worse survival probability in HD patients, however, only in univariate analysis. Additionally, the GG genotype in IL12A rs568408 was added as possible having relation with all-cause mortality.

IL-12 is a heterodimeric pro-inflammatory cytokine that stimulates the differentiation of Th1 cells [14]. It is formed by a $35-\mathrm{kDa}$ light chain (known as IL-12A or p35) and a $40-\mathrm{kDa}$ heavy chain (known as IL-12A or p40) [14]. The subunits IL-12A and IL12-B are encoded by $I L 12 A$ and $I L 12 B$, respectively, which are located on separate chromosomes (3p12-q13.2 and 5q31-33) [15]. IL-12 induces T-cell recruitment into the atherosclerotic plaque [16]. In the study by Mishra et al. [17], IL-12 correlated with endothelial dysfunction, insulin resistance and pro-inflammatory markers in type 2 diabetes patients. The minor allele in IL12A rs568408 has been associated with numerous neoplasms such as hepatocellular carcinoma [18], cervical cancer [19], colorectal cancer [20] or osteosarcoma [21]. IL12A rs568408 seems to be associated with autoimmune disorders: the A allele in IL12A rs568408 was found to be significantly higher in patients with Graves' disease than in controls [22]. According to Jiang et al. [23], patients with oral lichen planus were more likely to have the $I L 12 A$ rs568408 A allele and this allele was also associated with the severity of oral lichen planus. IL12A rs568404 might also contribute to the risk of asthma [24]. Abovementioned pathologic findings related to $I L 12 A$ rs568408 and IL-12A were not documented in HD patients yet. However, the GG genotype in IL12A rs568408 was shown as associated with the impaired antiHBs development in our previous studies on Caucasian
HD patients [12]. Additionally, there was a lower peak of anti-HBs titers in the GG genotype HD patients compared with those with one or two minor alleles [25]. In the study by Pan et al. [26], the T allele in IL12A rs2243115 contributed to the risk of low response to HBV vaccination in a Chinese Han population. In the current study group, anti-HBs generation was documented as a significant independent predictor of 6-year [10] and 7-year survival. The IL12A rs568408 GG genotype possessors revealed about $10 \%$ lower responders to $\mathrm{HBV}$ vaccination than the remaining patients, and they showed lower survival probability.

IFN- $\lambda 3$, a cytokine encoded by IFNL3, belongs to the family of type III IFNs and plays a role in the immune response through the activation of the Th1 pathway [27]. IFN- $\lambda 3$ was also found as up-regulator of indoleamine 2,3-dioxygenase (IDO) expression [28]. Increased IDO activity seems to skew helper T-cell polarization toward a Th2 phenotype [29]. IFN- $\lambda 3$ has been shown to be a potent antiviral molecule [30]. IFN- $\lambda 3$, similarly to other type III IFNs, is activated during bacterial infections [31]. IFNL3 is located on chromosomal region mapped to $19 \mathrm{q} 13$ [32]. rs12979860 and rs8099917 IFNL3 SNPs were involved in the production of IFN- $\lambda 3$ [33]. IFNL3 rs8099917 polymorphisms seem to be associated with IFN- $\lambda 3$ plasma levels also in HD subjects [34]. Major alleles of rs12979860 and rs8099917 have been found to influence the response of $\mathrm{HCV}$-infected patients to pegylated-IFN/ribavirin therapy [35]. IFNL3 polymorphisms were associated with spontaneous resolution of $\mathrm{HCV}$ infection in the general population [33] and in HD subjects [13] as well as IFN-related HBsAg seroclearance in chronic hepatitis B patients [36]. IFNL3 rs12979860 and rs8099917 polymorphisms have been found to affect the risk of hepatitis virus-related hepatocellular carcinoma [37]. Major alleles of IFNL3 are associated with less pronounced disturbances of lipid metabolism and less frequent steatosis and insulin resistance in chronic hepatitis C patients [38].

The GG genotype in IFNL3 rs8099917 was associated in the current study with worse survival of HD patients. The G allele in IFNL3 rs8099917 was attributed to lower circulating IFN- $\lambda 3$ than that shown in the TT genotype subjects [34]. Circulating IFN- $\lambda 3$ strongly correlates with anti-HBs production after HBV vaccination and infection in this group of patients [34]. However, a direct association between IFNL3 polymorphic variants and anti-HBs generation was not demonstrated [13], although both are related to survival of HD patients. This lack of such association may occur due to possibility that the association between plasma IFN- $\lambda 3$ and anti-HBs titers is also indirect. Our suggestion is that a link between them is provided by IDO which is involved in anti-HBs production [39]. At every step of anti-HBs production, 
additional factors, example related to uremic milieu and dialysis procedure [40], may disturb existing associations.

\section{Conclusions}

Polymorphisms of Th cell cytokine-associated genes (IFNL3 rs8099917, IL12A rs568408) are associated with survival on HD, however, they are not independent predictors of mortality in HD patients.

The independent association of anti-HBs with survival may be at least partially explained by polymorphisms in Th cell cytokine-associated genes.

\section{Additional file}

Additional file 1: Supplementary material for polymorphisms of T helper cell cytokine-associated genes in respect to survival of hemodialysis patients a prospective observational study. Description of data: Supplementary material contains characteristics, conditions for the identification and genotype distribution of the analyzed polymorphisms; characteristics of patients bearing different polymorphic variants of tested genes; cardiovascular, infection-related, and neoplasm-related mortality evaluated by the Kaplan-Meier analysis in respect of T helper cell cytokine genes; and haplotype and epistatic gene-gene interaction analyses. (DOCX 56 kb)

\section{Abbreviations}

ALP: Alkaline phosphatase; ALT: Alanine aminotransferase; Anti-HBc: Antibodies to core antigen of hepatitis B virus; Anti-HBs: Antibodies to surface antigen of hepatitis B virus; AST: Aspartate aminotransferase; CAD: Coronary artery disease; CCL2: Chemokine (C-C motif) ligand 2 gene; ESRD: End-stage renal disease; GGT: Gamma-glutamyl transferase; HBsAg: Surface antigen of hepatitis B virus; HBV: Hepatitis B virus; HCV: Hepatitis C virus; HD: Hemodialysis; HDF: Hemodiafiltration; HF-HD: High flux hemodialysis; HRM analysis: High Resolution Melt analysis; IDO: Indoleamine 2,3-dioxygenase; IFN: Interferon; IFNL3: Interferon lambda 3 gene; IL: Interleukin gene; IL4R: Interleukin 4 receptor gene; LF-HD: Low flux hemodialysis; N: Number of patients; PD: Peritoneal dialysis; PTH: Parathyroid hormone; RFLP analysis: Restriction Fragment Length Polymorphism analysis; RNA: Ribonucleic acid; RRT: Renal replacement therapy; SNP: Single nucleotide polymorphism; Th: T helper

\section{Acknowledgments}

We would like to express our gratitude to the physicians of the dialysis centers for their consent in collecting the participants' data.

The paper was presented at Kidney Week of the American Society of Nephrology held in November 15-20, 2016, in Chicago (Illinois, USA) and abstracted in J Am Soc Nephrol 2016:27 Abstract Suppl. 594A.

\section{Funding}

This study was supported by the Poznan University of Medical Sciences (PUMS), Poznań, Poland, grant numbers 502-01-02225363-03679 and 502-01-01124182-07474. PUMS authorities did not participate in the design of the study and collection, analysis, and interpretation of data and in writing the manuscript.

\section{Availability of data and materials}

The datasets used and/or analysed during the current study available from the corresponding author on reasonable request.

\section{Authors' contributions}

AEG made conception and design of the research; AEG and MKŚ performed the research; AM and PPJ did genotyping; $A E G, P P J$ and MKŚ made analysis and interpretation of data; WW performed statistical analysis and analyzed data; AEG wrote the paper. All authors read and approved the final manuscript.

\section{Competing interests}

The authors declare that they have no competing interests.

\section{Consent for publication}

Not applicable.

\section{Ethics approval and consent to participate}

The study design was approved by the Institutional Review Board of Poznan University of Medical Sciences, Poland. The written informed consent was obtained from all study participants. As the study included 3 subjects aged below 18 years $(14,64 ; 17.00 ; 17.47$ years), the written informed consent to participate was obtained from their parents.

\section{Publisher's Note}

Springer Nature remains neutral with regard to jurisdictional claims in published maps and institutional affiliations.

\section{Author details}

${ }^{1}$ Chair and Department of Nephrology, Transplantology and Internal Diseases, Poznan University of Medical Sciences, Przybyszewskiego 49, 60-355 Poznań, Poland. ${ }^{2}$ Student Nephrology Research Group, Chair and Department of Nephrology, Transplantology and Internal Diseases, Poznan University of Medical Sciences, 5, Poznań, Poland. ${ }^{3}$ Chair and Department of Biochemistry and Molecular Biology, Poznan University of Medical Sciences, Poznań, Poland. ${ }^{4}$ Chair and Department of Biophysics, Poznan University of Medical Sciences, Poznań, Poland.

Received: 18 October 2016 Accepted: 12 May 2017

Published online: 19 May 2017

\section{References}

1. Kimmel PL, Phillips TM, Simmens SJ, Peterson RA, Weihs KL, Alleyne S, et al. Immunologic function and survival in hemodialysis patients. Kidney Int. 1998:54:236-44

2. Badiou S, Cristol JP, Jaussent I, Terrier N, Morena M, Maurice F, et al. Finetuning of the prediction of mortality in hemodialysis patients by use of cytokine proteomic determination. Clin J Am Soc Nephrol. 2008;3:423-30.

3. Zhang J, Hua G, Zhang X, Tong R, Du X, Li Z. Regulatory T cells/T-helper cell 17 functional imbalance in uraemic patients on maintenance haemodialysis: a pivotal link between microinflammation and adverse cardiovascular events. Nephrology (Carlton). 2010;15:33-41.

4. Becker Y. Molecular immunological approaches to biotherapy of human cancers-a review, hypothesis and implications. Anticancer Res. 2006;26: 1113-34.

5. Kahraman S, Yilmaz R, Arici M, Altun B, Erdem Y, Yasavul U, et al. IL-10 genotype predicts serum levels of adhesion molecules, inflammation and atherosclerosis in hemodialysis patients. J Nephrol. 2006;19:50-6.

6. Liu Y, Berthier-Schaad Y, Fallin MD, Fink NE, Tracy RP, Klag MJ, et al. IL-6 haplotypes, inflammation, and risk for cardiovascular disease in a multiethnic dialysis cohort. J Am Soc Nephrol. 2006;17:863-70.

7. Bagci B, Bagci G, Candan F, Ozdemir O, Sezgin I. The protective effect of MCP-1 -2518 A>G promoter polymorphism in Turkish chronic renal failure patients requiring long-term hemodialysis. Int Urol Nephrol. 2015;47:551-6.

8. Balakrishnan VS, Guo D, Rao M, Jaber BL, Tighiouart H, Freeman RL, et al. Cytokine gene polymorphisms in hemodialysis patients: association with comorbidity, functionality, and serum albumin. Kidney Int. 2004;65:1449-60.

9. Świderska M, Mostowska A, Grzegorzewska AE. T helper cell related cytokine gene polymorphisms and vitamin D pathway gene polymorphisms as predictors of survival probability in patients on renal replacement therapy. Pol Arch Med Wewn. 2015;125:511-20.

10. Grzegorzewska AE, Świderska MK, Warchoł W. Antibodies to hepatitis B virus surface antigen and survival of hemodialysis patients - a prospective study. Expert Rev Vaccines. 2016;15:1063-74.

11. Grzegorzewska AE, Świderska MK, Mostowska A, Warchoł W, Jagodzinski PP. Polymorphisms of vitamin D signaling pathway genes and calcium sensing receptor gene in respect to survival of hemodialysis patients - a prospective observational study. Int J Endocrinol. 2016;2016:2383216.

12. Grzegorzewska AE, Wobszal PM, Sowińska A, Mostowska A, Jagodziński PP. Association of the interleukin-12 polymorphic variants with the development of antibodies to surface antigen of hepatitis B virus in hemodialysis patients in response to vaccination or infection. Mol Biol Rep. 2013;40:6899-911.

13. Grzegorzewska AE, Jodłowska E, Mostowska A, Jagodziński P. Effect of interferon $\lambda 3$ gene polymorphisms, rs8099917 and rs12979860, on response 
to hepatitis $B$ virus vaccination and hepatitis $B$ or $C$ virus infections among hemodialysis patients. Pol Arch Med Wewn. 2015;125:894-902.

14. Trinchieri $\mathrm{G}$. Interleukin-12 and the regulation of innate resistance and adaptive immunity. Nat Rev Immunol. 2003;3:133-46.

15. Grzegorzewska AE, Wobszal PM, Mostowska A, Jagodziński PP. Antibodies to hepatitis $B$ virus surface antigen and interleukin 12 and interleukin 18 gene polymorphisms in hemodialysis patients. BMC Nephrol. 2012;13:75.

16. Zhang X, Niessner A, Nakajima T, Ma-Krupa W, Kopecky SL, Frye RL, et al. Interleukin 12 induces T-cell recruitment into the atherosclerotic plaque. Circ Res. 2006;98:524-31.

17. Mishra M, Kumar H, Bajpai S, Singh RK, Tripathi K. Level of serum IL-12 and its correlation with endothelial dysfunction, insulin resistance, proinflammatory cytokines and lipid profile in newly diagnosed type 2 diabetes. Diabetes Res Clin Pract. 2011;94:255-61.

18. Liu L, Xu Y, Liu Z, Chen J, Zhang Y, Zhu J, et al. IL12 polymorphisms, HBV infection and risk of hepatocellular carcinoma in a high-risk Chinese population. Int J Cancer. 2011;128:1692-6.

19. Chen X, Han S, Wang S, Zhou X, Zhang M, Dong J, et al. Interactions of IL-12A and IL-12B polymorphisms on the risk of cervical cancer in Chinese women. Clin Cancer Res. 2009;15:400-5.

20. Sun R, Jia F, Liang Y, Li L, Bai P, Yuan F, et al. Interaction analysis of IL-12A and IL-12B polymorphisms with the risk of colorectal cancer. Tumour Biol. 2015;36:9295-301.

21. Wang J, Nong L, Wei Y, Qin S, Zhou Y, Tang Y. Association of interleukin-12 polymorphisms and serum IL-12p40 levels with osteosarcoma risk. DNA Cell Biol. 2013;32:605-10.

22. Guo T, Yang S, Liu N, Wang S, Cui B, Ning G. Association study of interleukin-12A gene polymorphisms with Graves' disease in two Chinese populations. Clin Endocrinol. 2011;74:125-9.

23. Jiang C, Yao H, Cui B, Zhou Y, Wang Y, Tang G. Association of interleukin $12 \mathrm{~A}$ gene polymorphisms with oral lichen planus in Chinese population. J Oral Pathol Med. 2015;44:602-6.

24. Chen T, Liang W, Gao L, Wang Y, Liu Y, Zhang L, et al. Association of single nucleotide polymorphisms in interleukin 12 (IL-12A and -B) with asthma in a Chinese population. Hum Immunol. 2011;72:603-6.

25. Jodłowska E, Mostowska A, Warchoł W, Jagodziński PP, Grzegorzewska AE. The peak titers of antibodies to the surface antigen of hepatitis B virus after vaccination in relation to polymorphisms in the immunity-related genes - a prospective study among hemodialysis patients. Amsterdam: Abstr. 10th Vaccine Congress; 2016.

26. Pan L, Zhang W, Liang Z, Wu X, Zhu X, Li J, et al. Association between polymorphisms of the cytokine and cytokine receptor genes and immune response to hepatitis B vaccination in a Chinese Han population. J Med Virol. 2012;84:26-33.

27. Kelly C, Klenerman P, Barnes E. Interferon lambdas: the next cytokine storm. Gut. 2011;60:1284-93.

28. Fox JM, Crabtree JM, Sage LK, Tompkins SM, Tripp RA. Interferon lambda upregulates IDO1 expression in respiratory epithelial cells after influenza virus infection. J Interf Cytokine Res. 2015;35:554-62.

29. Xu H, Oriss TB, Fei M, Henry AC, Melgert BN, Chen L, et al. Indoleamine 2,3dioxygenase in lung dendritic cells promotes Th2 responses and allergic inflammation. Proc Natl Acad Sci U S A. 2008;105:6690-5.

30. Dellgren C, Gad HH, Hamming OJ, Melchjorsen J, Hartmann R. Human interferon-lambda3 is a potent member of the type III interferon family. Genes Immun. 2009;10:125-31.

31. Cohen TS, Parker D. Microbial pathogenesis and type III interferons. Cytokine Growth Factor Rev. 2016;29:45-51.

32. Sugiyama M, Tanaka Y, Wakita T, Nakanishi M, Mizokami M. Genetic variation of the IL-28B promoter affecting gene expression. PLoS One. 2011;6:e26620.

33. Shi $X$, Pan $Y$, Wang M, Wang D, Li W, Jiang T, et al. IL28B genetic variation is associated with spontaneous clearance of hepatitis $C$ virus, treatment response, serum IL-28B levels in Chinese population. PLoS One. 2012;7:e37054.

34. Grzegorzewska AE, Świderska MK, Mostowska A, Warchoł W, Jagodziński PP. Antibodies to HBV surface antigen in relation to interferon- $\lambda 3$ in hemodialysis patients. Vaccine. 2016;34:4866-74.

35. Li S, Hu P, Zhang QQ, Liu YH, Hu HD, Zhang DZ, et al. Single nucleotide polymorphisms of the IL28B and sustained virologic response of patients with chronic hepatitis C to PEG-interferon/ribavirin therapy: a meta-analysis: meta-analysis of IL28B. Hepat Mon. 2011;11:163-72.

36. Lampertico P, Viganò M, Cheroni C, Facchetti F, Invernizzi F, Valveri V, et al. IL28B polymorphisms predict interferon-related hepatitis B surface antigen seroclearance in genotype $D$ hepatitis $B$ e antigen-negative patients with chronic hepatitis B. Hepatology. 2013;57:890-6.

37. Zhang Y, Zhu SL, Chen J, Li LQ. Meta-analysis of associations of interleukin-28B polymorphisms rs8099917 and rs12979860 with development of hepatitis virus-related hepatocellular carcinoma. Onco Targets Ther. 2016;9:3249-57.

38. Eslam M, Booth DR, George J, Ahlenstiel G. Interaction of IFNL3 with insulin resistance, steatosis and lipid metabolism in chronic hepatitis $C$ virus infection. World J Gastroenterol. 2013;19:7055-61.

39. Eleftheriadis T, Sparopoulou T, Antoniadi G, Liakopoulos V, Stefanidis I, Galaktidou G. Suppression of humoral immune response to hepatitis B surface antigen vaccine in BALB/c mice by 1-methyl-tryptophan $\mathrm{CO}$ administration. Daru. 2011;19:236-9.

40. Grzegorzewska AE, Świderska MK, Warchoł W. Post-vaccination anti-HBs titers and modality of dialysis treatment in uremic patients. Amsterdam: Abstr. 10th Vaccine Congress; 2016.

\section{Submit your next manuscript to BioMed Central and we will help you at every step:}

- We accept pre-submission inquiries

- Our selector tool helps you to find the most relevant journal

- We provide round the clock customer support

- Convenient online submission

- Thorough peer review

- Inclusion in PubMed and all major indexing services

- Maximum visibility for your research

Submit your manuscript at www.biomedcentral.com/submit
Biomed Central 